\title{
Off-pump coronary artery bypass grafting versus optimal medical therapy: effectiveness of incomplete surgical myocardial revascularization in high-risk patients with multi-vessel coronary artery disease
}

\author{
Cristiano Spadaccio ${ }^{1 *}$, Antonio Nenna ${ }^{1}$, Filippo Prestipino ${ }^{2}$, Gwyn W Beattie ${ }^{1}$, Francesco Nappi ${ }^{3}$, Massimo Chello ${ }^{1}$, \\ Fraser W Sutherland ${ }^{1}$
}

From World Society of Cardiothoracic Surgeons 25th Anniversary Congress, Edinburgh Edinburgh, UK. 19-22 September 2015

\section{Background/Introduction}

High-risk patients with multivessel disease (MVD) represent a surgical challenge carrying high mortality risk. These cases elicit discussion within heart teams regarding the actual benefit of undertaking major surgery on these patients and often lead to abandon the surgical option. Off-pump coronary artery bypass (OPCAB) provides good quality graft on left anterior descending (LAD) without exposing the patient to cardiopulmonary bypass, and, despite providing an incomplete revascularization, might be the ideal choice in patients with multiple comorbidities, not eligible to percutaneous or on-pump procedures.

\section{Aims/Objectives}

To compare survival in high-risk patients with MVD and no percutaneous option, treated with incomplete off-pump surgical myocardial revascularization or discharged on optimal medical therapy.

\section{Method}

83 high-risk patients with MVD were enrolled: 42 were treated with incomplete off-pump revascularization using left internal mammary artery (LIMA) to LAD; 41 were treated with optimal medical therapy (OMT), having refused surgery. Patients were followed-up by

${ }^{1}$ Department of Cardiothoracic Surgery, Golden Jubilee National Hospital, Glasgow, G814DY, UK

Full list of author information is available at the end of the article telephone interview. Primary endpoint was survival from all-cause mortality; secondary endpoints were survival from cardiac-related mortality and freedom from nonfatal major adverse cardiac events (MACE).

\section{Results}

During follow up, there were 11 deaths in OPCAB group and 27 deaths in OMT group. Death was due to cardiac factors in 6 and 15 patients, respectively. MACEs were observed in 6 patients in OPCAB group and 4 patients in OMT group. Both survival from allcause mortality and cardiac-related events were in favor of the OPCAB group over the OMT which carried a propensity score-adjusted hazard ratio of 3.862 and 3.663, for all-cause and cardiac-related mortality respectively. There was no statistically significant difference concerning freedom from MACE.

\section{Discussion/Conclusion}

For high-risk patients with MVD, considered ineligible for on-pump complete revascularization surgery or percutaneous coronary intervention, incomplete revascularization with OPCAB LIMA-on-LAD offers benefits in survival when compared to OMT alone.

\footnotetext{
Authors' details

${ }^{1}$ Department of Cardiothoracic Surgery, Golden Jubilee National Hospital, Glasgow, G814DY, UK. ²Department of Cardiac Surgery University Campus Bio-Medico of Rome, Rome, Italy. ${ }^{3}$ Cardiac Surgery, Centre Cardiologique du Nord de Saint-Denis, Paris, France.
} 
doi:10.1186/1749-8090-10-S1-A351

Cite this article as: Spadaccio et al:: Off-pump coronary artery bypass grafting versus optimal medical therapy: effectiveness of incomplete surgical myocardial revascularization in high-risk patients with multivessel coronary artery disease. Journal of Cardiothoracic Surgery 2015 10(Suppl 1):A351.

Submit your next manuscript to BioMed Central and take full advantage of:

- Convenient online submission

- Thorough peer review

- No space constraints or color figure charges

- Immediate publication on acceptance

- Inclusion in PubMed, CAS, Scopus and Google Scholar

- Research which is freely available for redistribution

Submit your manuscript at www.biomedcentral.com/submit
Ciomed Central 